\title{
Low cost medium for recombinant endoglucanase II production by Pichia pastoris
}

\author{
Sakunwan Orachun ${ }^{1,3,4}$, Waraporn Malilas ${ }^{4,5}$, Nassapat Boonvitthya ${ }^{2}$, Vorakan Burapatana ${ }^{2}$ \\ and Warawut Chulalaksananukul ${ }^{3,4,5 *}$ \\ ${ }^{1}$ Program in Biotechnology, Faculty of Science, Chulalongkorn University, 254 Phayathai Road, Pathumwan, Bangkok \\ 10330, Thailand. \\ ${ }^{2}$ PTT Research and Technology Institute, PTT Public Co. Ltd., Wangnoi, Ayutthaya 13170, Thailand. \\ ${ }^{3}$ Department of Botany, Faculty of Science, Chulalongkorn University, 254 Phayathai Road, Pathumwan, Bangkok \\ 10330, Thailand. \\ ${ }^{4}$ Biofuels by Biocatalysts Research Unit, Chulalongkorn University, 254 Phayathai Road, Pathumwan, Bangkok 10330, \\ Thailand. \\ ${ }^{5}$ Aquatic Resources Research Institute, Chulalongkorn University, 254 Phayathai Road, Pathumwan, Bangkok 10330, \\ Thailand.
}

\begin{abstract}
The suitability of crude glycerol (75\% (v/v) glycerol content) from a biodiesel production plant, and soybean meal and rice bran hydrolysates as replacements in the culture medium for commercially available glycerol, peptone and yeast extract, respectively, to form a low cost culture medium for the growth of, and recombinant endoglucanase II production by, Pichia pastoris was evaluated. The use of $1 \%(\mathrm{v} / \mathrm{v})$ crude glycerol as a carbon source, and a mixture of $0.175 \%(\mathrm{v} / \mathrm{v})$ soybean meal and $0.15 \%(\mathrm{v} / \mathrm{v})$ rice bran hydrolysate in the presence of $0.5 \%(\mathrm{w} / \mathrm{v})$ ammonium sulfate was found to be a suitable medium in the presence of $3 \%(\mathrm{v} / \mathrm{v})$ methanol as the inducer. Under these conditions, the highest level of extracellular endoglucanase II activity $(61.5 \mathrm{U} / \mathrm{mL})$ was found after $120 \mathrm{~h}$ culture at $30^{\circ} \mathrm{C}$ and $\mathrm{pH} 6.0$.
\end{abstract}

Key words: Biodiesel glycerol, soybean meal, rice bran, endoglucanase II, Pichia pastoris.

\section{INTRODUCTION}

The high cost of nutrient medium for the cultivation of recombinant Pichia pastoris in the production of recombinant proteins is a major factor that needs to be considered and optimized for large scale production (Yadav et al., 2011). Therefore, the development of a suitable culture medium using low cost raw materials is of interest. The growth and recombinant protein production level in recombinant $P$. pastoris depends on various conditions and on the composition of the culture medium (Batista et al., 2013).

$P$. pastoris is a methylotrophic yeast that is widely used as a host for the production of recombinant proteins.

*Corresponding author. E-mail: warawut.c@chula.ac.th. Tel: +66 22185482. Fax: +66 22185482.

Author(s) agree that this article remain permanently open access under the terms of the Creative Commons Attribution License 4.0 $\underline{\text { International License }}$ 
Recently, the improvement of individual cellulase enzymes from Trichoderma reesei has been attempted by genetic engineering in $P$. pastoris in order to enhance their cellulose degradation ability (Boonvitthya et al., 2013).

Cellulases, which degrade cellulose, consist of endoglucanases (EGs), cellobiohydrolases and betaglucosidases. The EGs act on the amorphous regions of cellulose, and EGII is one of the most abundant EGs produced by $T$. reesei and has the highest catalytic efficiency (Qin et al., 2008; Zhang et al., 2012).

The estimated cost of enzyme production at an industrial scale depends to a large extent upon the growth medium used in the process (Hajii et al., 2008; Batista et al., 2013). Previous studies have reported on the fermentation using pure glycerol as the carbon substrate because the salts in raw glycerol exert important inhibitory effects on many microorganisms (Petitdemange et al., 1995). However, yeast strains that can grow on raw glycerol have been reported (Papanikolaou et al., 2002). In order to reduce the medium costs, the crude glycerol produced during biodiesel manufacturing, which contains macro elements, such as calcium, potassium, magnesium, sulfur and sodium (Kitcha and Cheirsilp, 2011), has been used as a carbon source in $P$. pastoris culture medium to increase the cell concentration in the logarithmic growth phase (Celik et al., 2008). In addition, the waste agricultural products of soybean meal and rice bran have been used as organic nitrogen sources since they provide a rich but inexpensive source of nutrients (Xiao et al., 2007; Sereewatthanawut et al., 2008).

The aim of this study was to determine the suitability of crude glycerol, obtained as the by-product of biodiesel production, and soybean meal and rice bran as a substitute for high purity commercial glycerol, peptone and yeast extract, respectively, in the formation of a low cost culture medium for the growth of, and recombinant (r)EGIl production by, P. pastoris.

\section{MATERIALS AND METHODS}

\section{Microbial strain}

The genetically engineered $P$. pastoris $\mathrm{X}-33$ yeast strain, which is transfected with the pPICZ $\alpha A$ plasmid encoding for the $T$. reesei EGIl gene under the methanol inducible $A O X 1$ promoter (Boonvitthya et al., 2013) was provided by the Biocatalysts Research Unit, Chulalongkorn University. The transformed line was maintained on YPD $(2 \%(\mathrm{w} / \mathrm{v})$ peptone, $1 \%(\mathrm{w} / \mathrm{v})$ yeast extract and $2 \%(\mathrm{w} / \mathrm{v})$ dextrose) agar. Expression of the rEGIl as a secretory product was controlled under the methanol inducible AOX1 promoter and repressed by glycerol.

Preparation of crude glycerol, the byproduct of biodiesel production

The crude glycerol was obtained from the Energy Absolute Public Co. Ltd., biodiesel production plant at Kabinburi Industrial Zone in
Prachinburi, Thailand, which uses refined bleached deodorized palm oil and methanol in the transesterification process with an alkaline catalyst. This crude glycerol preparation contained $75 \%$ $(\mathrm{v} / \mathrm{v})$ glycerol and so the volume of this crude glycerol added to the medium was set accordingly to give the desired final glycerol concentration $(\mathrm{v} / \mathrm{v})$ ignoring the impurities. The crude glycerol was adjusted to $\mathrm{pH} 7.0$ prior to addition to the culture medium.

\section{Preparation of soybean meal and rice bran hydrolysates}

Soybean meal was obtained from Lactasoy Co. Ltd., Prachinburi, Thailand, while rice bran was obtained from a rice mill in Pathumthani, Thailand, and separately treated in $1 \mathrm{~N}$ sulfuric acid $\left(\mathrm{H}_{2} \mathrm{SO}_{4}\right)$ at $33 \%(\mathrm{w} / \mathrm{v})$. Each mixture was autoclaved at $121^{\circ} \mathrm{C}$ for 40 min, cooled down and distilled water added to the required volume as well as $10 \mathrm{~N} \mathrm{NaOH}$ to set the $\mathrm{pH}$ to 7.0 . The suspension was then filtered and the filtrate stored at $4^{\circ} \mathrm{C}$ until use. The total nitrogen content was analyzed by the Kjeldahl method (AOAC, 1990).

\section{Medium optimization by a sequential univariate approach}

The effect of the nutrient composition, in terms of the concentration of crude glycerol, methanol, soybean meal and rice bran hydrolysates and ammonium sulfate, as well as the medium $\mathrm{pH}$ and culture temperature and time, was investigated upon the growth of, and the production of rEGII by, $P$. pastoris in that order as follows.

For the initial growth of $P$. pastoris to form the starter inoculum, the crude glycerol concentration was varied in BMGY medium (1\% $(\mathrm{w} / \mathrm{v})$ yeast extract, $2 \%(\mathrm{w} / \mathrm{v})$ peptone, $100 \mathrm{mM}$ potassium phosphate buffer $\mathrm{pH} 6.0,0.4 \%(\mathrm{v} / \mathrm{v})$ Pichia trace minerals (PTM) and $1 \%(\mathrm{v} / \mathrm{v})$ glycerol) by substitution of the pure glycerol with the crude glycerol preparation at a final glycerol concentration of $0,0.5$, $1,1.5,2$ and $2.5 \%(\mathrm{v} / \mathrm{v})$. $P$. pastoris was grown in each of these media $(50 \mathrm{~mL})$ in $250-\mathrm{mL}$ baffled flasks at $30^{\circ} \mathrm{C}$ with shaking at 250 rpm for $21 \mathrm{~h}$. The growth of the yeast was then monitored in terms of the yeast dry cell weight (DCW) and optical density, as detailed below.

For the induction of rEGIl production by the recombinant $P$. pastoris, the yeast was first grown in the optimum crude glycerol concentration supplemented BMGY medium (BMcGY), harvested by centrifugation $(10,000 \mathrm{xg}, 3 \mathrm{~min})$, washed in sterile water and then resuspended and transferred into $100 \mathrm{~mL}$ BMMY medium (as per BMGY except the glycerol was replaced with methanol) except that the methanol concentration was varied at $0,0.5,1,2,3$ and $4 \%$ $(\mathrm{v} / \mathrm{v})$ for induction of the AOX-1 promoter and as a carbon source for the yeast. The cell suspension was then grown in $250-\mathrm{mL}$ baffled flasks at $30^{\circ} \mathrm{C}$ with shaking at $250 \mathrm{rpm}$ for $144 \mathrm{~h}$. For each selected methanol concentration, the same amount (final concentration) of fresh methanol was added to the culture each day $(0,24,48,72,96$ and $120 \mathrm{~h})$. At 12, $24 \mathrm{~h}$ and then every $24 \mathrm{~h}$ thereafter a $5-\mathrm{mL}$ aliquot of the cell suspension was removed to ascertain the yeast DCW and extracellular rEGII activity.

The effect of substitution of peptone with soybean meal hydrolysate (at $0,0.025,0.05,0.1,0.125,0.15,0.175$ and $0.2(\mathrm{v} / \mathrm{v})$ ) upon $P$. pastoris growth in the BMcGY medium (optimal crude glycerol level determined as above), and upon the subsequent growth and rEGIl production level in BMMY medium was then evaluated as above, except using the optimal methanol concentration in the BMMY medium, respectively.

The replacement of both the peptone and yeast extract in the BMGY and BMMY media with a combined organic nitrogen source of soybean meal and rice bran hydrolysates was then evaluated as above, except using the optimal soybean hydrolysate level and varying the rice bran hydrolysate at $0,0.1,0.25,0.5,1.0,1.5$ and $2.0 \%(\mathrm{v} / \mathrm{v})$ in place of the yeast extract. 
Table 1. Effect of the crude glycerol concentration as a replacement for pure glycerol in BMGY medium on the growth of recombinant $P$. pastoris.

\begin{tabular}{lc}
\hline $\begin{array}{l}\text { Crude glycerol concentration } \\
(\%(\mathrm{v} / \mathrm{v}))\end{array}$ & $\begin{array}{c}\text { Dry cell weight } \\
(\mathrm{g} / \mathrm{L})^{\mathrm{a}}\end{array}$ \\
\hline 0 & $2.08 \pm 0.07$ \\
0.5 & $4.02 \pm 0.10$ \\
1.0 & $8.17 \pm 0.06$ \\
1.5 & $7.61 \pm 0.13$ \\
2.0 & $6.22 \pm 0.03$ \\
2.5 & $5.58 \pm 0.17$ \\
\hline
\end{tabular}

${ }^{\text {a } D a t a}$ are shown as the mean \pm 1 SD and are derived from triplicate experiments. Means followed by a different lowercase letter are significantly different $(P<0.05$; ANOVA, DMRT).

Next, the optimal modified BMcGY and BMMY media were supplemented with ammonium sulfate at $0,0.1,0.5,1,1.5$ and $2 \%$ $(w / v)$ and the growth or growth and rEGIl production levels, respectively, were evaluated as above. Finally, the effect of the $\mathrm{pH}$ (5.5 to 7.0) of the optimal media, followed by that of the cultivation temperature $\left(25\right.$ to $\left.35^{\circ} \mathrm{C}\right)$, upon the recombinant $P$. pastoris growth and $\mathrm{rEG}$ II production levels was evaluated in the same manner.

\section{Analytical methods}

\section{Enzyme assay}

The evaluation of the extracellular rEGII activity in the culture supernatant assay was performed by monitoring the hydrolysis of carboxymethyl cellulose (CMC) as the total reducing sugar, evaluated using the dinitrosalicylic acid DNS method (Miller, 1959). Each reaction contained $0.5 \mathrm{~mL}$ of $2 \%(\mathrm{w} / \mathrm{v}) \mathrm{CMC}$ solution in $50 \mathrm{mM}$ acetate buffer $(\mathrm{pH} \mathrm{4.8)}$ and $0.5 \mathrm{~mL}$ of the diluted test enzyme solution. The reaction was incubated at $50^{\circ} \mathrm{C}$ for $30 \mathrm{~min}$ and then 3 $\mathrm{mL}$ of DNS reagent was added, incubated in a boiling water bath for $5 \mathrm{~min}$, and then cooled. Thereafter, the absorbance was measured at $540 \mathrm{~nm}$ to estimate the quantity of reducing sugars produced in the assay (Miller, 1959). One unit (U) of enzyme activity was defined as the amount of enzyme that released $1 \mu \mathrm{mol}$ of reducing sugar $/ \mathrm{mL} / \mathrm{min}$ under the above assay conditions. Glucose $(0-2$ $\mu \mathrm{g} / \mathrm{mL}$ ) was used to form the standard curve.

\section{Measurement of protein concentration}

The total protein content was determined following the method of Bradford (1976) using bovine serum albumin $(0-25 \mu \mathrm{g} / \mathrm{mL})$ as a standard and measuring the absorbance at $595 \mathrm{~nm}$ with a microplate reader (ANTHOS Zenyth 200, USA).

\section{Determination of yeast cell concentration}

The yeast DCW was determined by centrifugation $(5000 \mathrm{xg}$ for 5 min) of $5 \mathrm{~mL}$ of the culture broth, washing the cells with distilled water, and then drying at $105^{\circ} \mathrm{C}$ for $24 \mathrm{~h}$. From the obtained mass and the starting culture volume analyzed the DCW was then calculated $(\mathrm{g} / \mathrm{L})$. In addition, the yeast cell concentration was estimated in terms of the optical density (OD) of the suspension at $600 \mathrm{~nm}\left(\mathrm{OD}_{600}\right)$ AS compared to the medium alone (Charoenrat et al., 2013).

\section{Data analysis}

Data WEre presented as the mean \pm one standard deviation (SD). The statistical significance of the difference between means was tested by analysis of variance (ANOVA) and Duncan's multiple range tests (DMRT), with significance accepted at the $P<0.05$ level.

\section{RESULTS AND DISCUSSION}

In this study, different cultivation media compositions and cultivation conditions were evaluated in order to attempt to reduce the cost of efficient rEGIl production by $P$. pastoris. The culture medium composition is known to be a major influence on the growth and enzyme production, especially the carbon and nitrogen sources (Broach, 2012; Charoenrat et al., 2013).

\section{Effectiveness of crude glycerol to replace commercially available glycerol in high cell density cultivation of $P$. pastoris in BMGY medium}

Glycerol is regularly used as the principal initial carbon source in $P$. pastoris cultivation in order to increase the cell concentration. When utilizing the cheaper crude glycerol, a surplus byproduct of the expanding biodiesel production industry, in the BMGY medium, the highest level of yeast biomass production $(8.17 \mathrm{~g} / \mathrm{L}$, DCW basis) was obtained with $1 \%(\mathrm{v} / \mathrm{v})$ of biodiesel glycerol (Table 1$)$. Crude glycerol concentrations above or below $1 \%(\mathrm{v} / \mathrm{v})$ resulted in a lower yeast yield, in accord with the previously reported repression of yeast growth at high crude glycerol levels (Tang et al., 2009). Accordingly, $P$. pastoris was initially grown in BMGY medium with $1 \%$ $(\mathrm{v} / \mathrm{v})$ crude glycerol in place of the commercial glycerol (hereafter called BMcGY). Although this was a similar glycerol concentration to the commercial glycerol containing BMcGY medium, a likely economic saving would still be gained since, as compared to the pure glycerol (US\$1.11 per $\mathrm{kg}$ ), the crude glycerol is some tenfold cheaper (US\$0.11 per $\mathrm{kg}$ ). Indeed, as a cheaper carbon source for biotechnological applications that may make them economically feasible, crude glycerol has been used as carbon source in many industrial fermentations (Chatzifragkou et al., 2011). However, the crude glycerol derived from biodiesel production typically possesses a low glycerol concentration of low value because of the impurities. Further refining of the crude glycerol will depend on the economy of production scale and/or the availability of a glycerol purification facility (Naresh and Brian, 2006).

\section{Effects of the methanol concentration on BMMY medium}

Methanol is typically the widely accepted industrial choice 


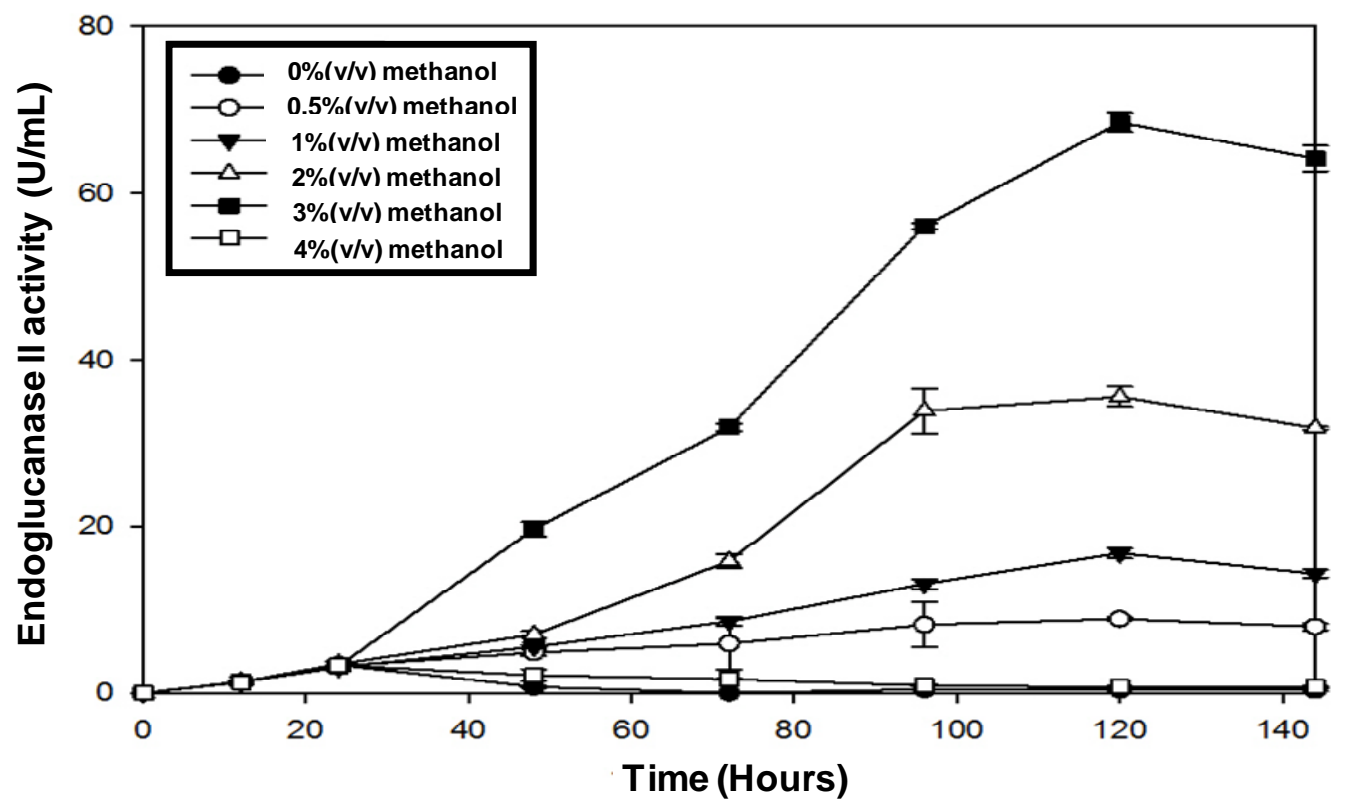

Figure 1. Effect of the methanol concentration on the growth of, and the extracellular recombinant endoglucanase II production $(\mathrm{U} / \mathrm{mL})$ level by, recombinant $P$. pastoris in BMMY medium. Data are shown as the mean $\pm 1 \mathrm{SD}$ and are derived from triplicate experiments.

Table 2. The growth of recombinant $P$. pastoris in BMcGY $^{a}$ medium with different soybean meal hydrolysate concentrations as a replacement for the peptone.

\begin{tabular}{lc}
\hline $\begin{array}{l}\text { Soybean meal hydrolysate } \\
(\%(\mathrm{v} / \mathrm{v}))\end{array}$ & $\begin{array}{c}\text { Dry cell weight } \\
(\mathbf{g} / \mathbf{L})^{\mathbf{b}}\end{array}$ \\
\hline 0.0000 & $4.57 \pm 0.17$ \\
0.0125 & $5.35 \pm 0.05$ \\
0.0250 & $6.21 \pm 0.10$ \\
0.0500 & $6.63 \pm 0.13$ \\
0.0750 & $7.04 \pm 0.09$ \\
0.1000 & $7.25 \pm 0.10$ \\
0.1250 & $7.41 \pm 0.11$ \\
0.1500 & $7.67 \pm 0.04$ \\
0.1750 & $8.01 \pm 0.13$ \\
0.2000 & $6.13 \pm 0.12$ \\
\hline
\end{tabular}

${ }^{\mathrm{a}} \mathrm{BMCGY}=\mathrm{BMGY}$ medium but with the $2 \%(\mathrm{v} / \mathrm{v})$ pure glycerol replaced with $1 \%(\mathrm{v} / \mathrm{v})$ crude glycerol $(75 \%$ (v/v) glycerol) from a biodiesel production plant. ${ }^{b}$ Data are shown as the mean \pm 1 SD and are derived from triplicate experiments. Means followed by a different lowercase letter are significantly different $(P<0.05$; ANOVA, DMRT).

of carbon source for $P$. pastoris fermentations, and also serves as the inducer for recombinant protein expression under the control of the $A O X 1$ promoter of $P$. pastoris. Following the initial growth of $P$. pastoris in BMcGY medium and transfer to BMMY medium without methanol no rEGII production was detected, as expected with the
AOX1 promoter. Increasing the methanol concentration up to $3 \%(\mathrm{v} / \mathrm{v})$ correspondingly increased the rEGII level produced, especially at 2 and $3 \%(\mathrm{v} / \mathrm{v})$ methanol, with the highest $\mathrm{rEG}$ II level obtained $(68.5 \mathrm{U} / \mathrm{mL})$ at $3 \%(\mathrm{v} / \mathrm{v})$ methanol after $120 \mathrm{~h}$ (Figure 1). Increasing the methanol concentration further to $4 \%(\mathrm{v} / \mathrm{v})$, however, resulted in almost no rEGII production, consistent with that previously reported in the production of human serum albumen in this yeast (Bushell et al., 2003). Accordingly, a methanol concentration of $3 \%(\mathrm{v} / \mathrm{v})$ was used in the BMMY medium (hereafter called $\mathrm{BMM}_{3} \mathrm{Y}$ ).

\section{Effect of organic nitrogen sources}

As determined by Kjeldahl's method, the total nitrogen content of the soybean meal and rice bran hydrolysates were 0.52 and $0.31 \%(\mathrm{w} / \mathrm{v})$, respectively, as compared to $\sim 12 \%$ and $\sim 9.5 \%(\mathrm{w} / \mathrm{v}$ ) (Technical Data from HiMedia Laboratories Pvt. Ltd.) for the peptone and yeast extract, respectively.

\section{Soybean meal hydrolysate replacement for peptone}

The use of soybean meal hydrolysate in place of peptone in the BMcGY medium was found to support the growth of $P$. pastoris, with an increasing yeast yield being obtained with an increasing soybean meal hydrolysate concentration up to a maximum yeast yield $(8.01 \mathrm{~g} / \mathrm{L}$, DCW basis) at $0.175 \%(\mathrm{v} / \mathrm{v})$ soybean hydrolysate (Table 2). This compared reasonably well with the $8.17 \mathrm{~g} / \mathrm{L}$ (DCW basis) obtained with the peptone containing 


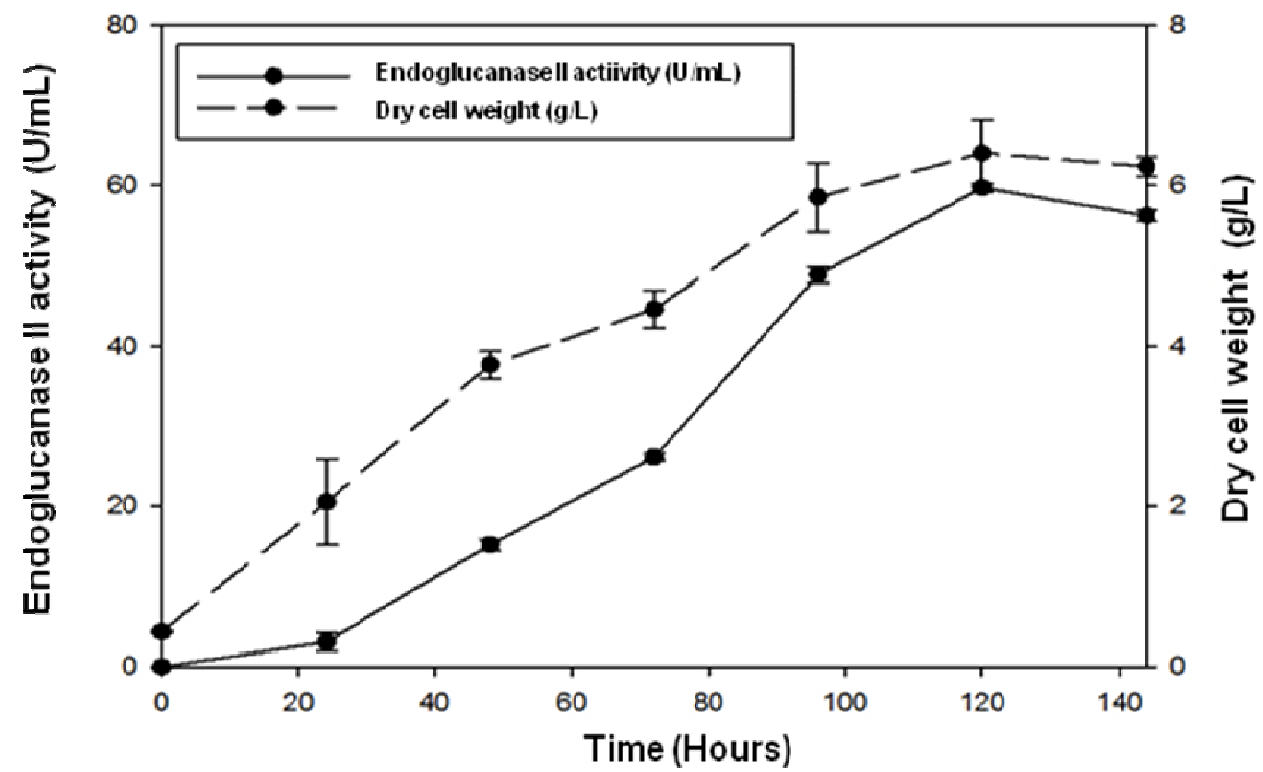

Figure 2. The growth of, and the extracellular recombinant endoglucanase II production $(\mathrm{U} / \mathrm{mL})$ level by, recombinant $P$. pastoris over time when grown in $\mathrm{BMM}_{3} \mathrm{YS}$ media (soybean meal hydrolysate at $0.175 \%(\mathrm{v} / \mathrm{v})$ as a replacement for peptone in the $\mathrm{BMM}_{3} \mathrm{Y}$ media). Data are shown as the mean \pm 1 SD and are derived from triplicate experiments.

Table 3. Effect of increasing rice bran hydrolysate concentration as a replacement for yeast extract in BMcGYS ${ }^{a}$ medium on the growth of recombinant $P$. pastoris.

\begin{tabular}{lc}
\hline $\begin{array}{l}\text { Rice bran hydrolysate } \\
(\%(\mathbf{v} / \mathbf{v}))\end{array}$ & $\begin{array}{c}\text { Dry cell weight } \\
(\mathbf{g} / \mathrm{L})\end{array}$ \\
\hline 0.0000 & $4.86 \pm 0.12$ \\
0.0125 & $5.28 \pm 0.15$ \\
0.0250 & $6.12 \pm 0.19$ \\
0.0500 & $6.48 \pm 0.05$ \\
0.0750 & $6.93 \pm 0.09$ \\
0.1000 & $7.14 \pm 0.23$ \\
0.1250 & $7.32 \pm 0.09$ \\
0.1500 & $8.12 \pm 0.11$ \\
0.1750 & $7.81 \pm 0.22$ \\
0.2000 & $7.46 \pm 0.10$ \\
\hline a BMcGYS = BMGY medium but with the 2\% \\
(v/v) pure glycerol and 1\% (w/v) peptone \\
replaced with 1\% (v/v) crude glycerol $(75 \%(\mathrm{v} / \mathrm{v})$ \\
glycerol) from a biodiesel production plant and \\
$0.175 \%(\mathrm{v} / \mathrm{v})$ soy meal hydrolysate, respectively. \\
bata are shown as the mean \pm 1 SD and are \\
derived from triplicate experiments. Means \\
followed by a different lowercase letter are \\
significantly different $(P<0.05 ;$ ANOVA, DMRT). \\
\hline
\end{tabular}

BMcGY medium. Accordingly, the BMcGY and $\mathrm{BMM}_{3} \mathrm{Y}$ media were modified to contain $0.175 \%(\mathrm{v} / \mathrm{v})$ soybean meal hydrolysate in place of peptone (hereafter called $B M c G Y S$ and $B M M_{3} Y S$, respectively).
When $P$. pastoris was cultured and induced in the $\mathrm{BMM}_{3} \mathrm{YS}$ medium, the modified medium was found to support rEGIl production, with a maximum level (59.7 $\mathrm{U} / \mathrm{mL}$ ) being obtained after $120 \mathrm{~h}$ (Figure 2). Although this was 1.15-fold lower than that with the peptone containing $\mathrm{BMM}_{3} \mathrm{Y}$ medium, a likely economic saving is still gained $\quad(\sim 99.4 \%$ decrease; http: //www.quotenet.com/commodities/soybean-meal-price and HiMedia Laboratories Pvt. Ltd.). Note that the yeast yield obtained in the modified $\mathrm{BMM}_{3} \mathrm{YS}$ medium essentially correlated with the obtained rEGII production level. Thus, soybean meal hydrolysate has the potential to be employed as a peptone replacement.

\section{Rice bran hydrolysate replacement for yeast extract}

The use of rice bran hydrolysate in place of peptone in the modified BMcGYS medium was found to support the growth of $P$. pastoris, with an increasing yeast yield being obtained with increasing soybean meal hydrolysate concentrations up to a maximum (8.12 g/L, DCW basis) at $0.15 \%(\mathrm{v} / \mathrm{v})$ (Table 3$)$. This compared reasonably well with the $8.17 \mathrm{~g} / \mathrm{L}$ (DCW basis) obtained with the peptone containing BMcGY medium. Accordingly, the BMcGYS and $\mathrm{BMM}_{3} \mathrm{YS}$ media were further modified to contain $0.15 \%(\mathrm{w} / \mathrm{v})$ rice bran hydrolysate in place of yeast extract, hereafter called BMcGYSR and $\mathrm{BMM}_{3} \mathrm{YSR}$, respectively.

When $P$. pastoris was cultured and induced in the $\mathrm{BMM}_{3} \mathrm{YSR}$ medium, the modified medium was found to support rEGIl production reasonably well but not to as 


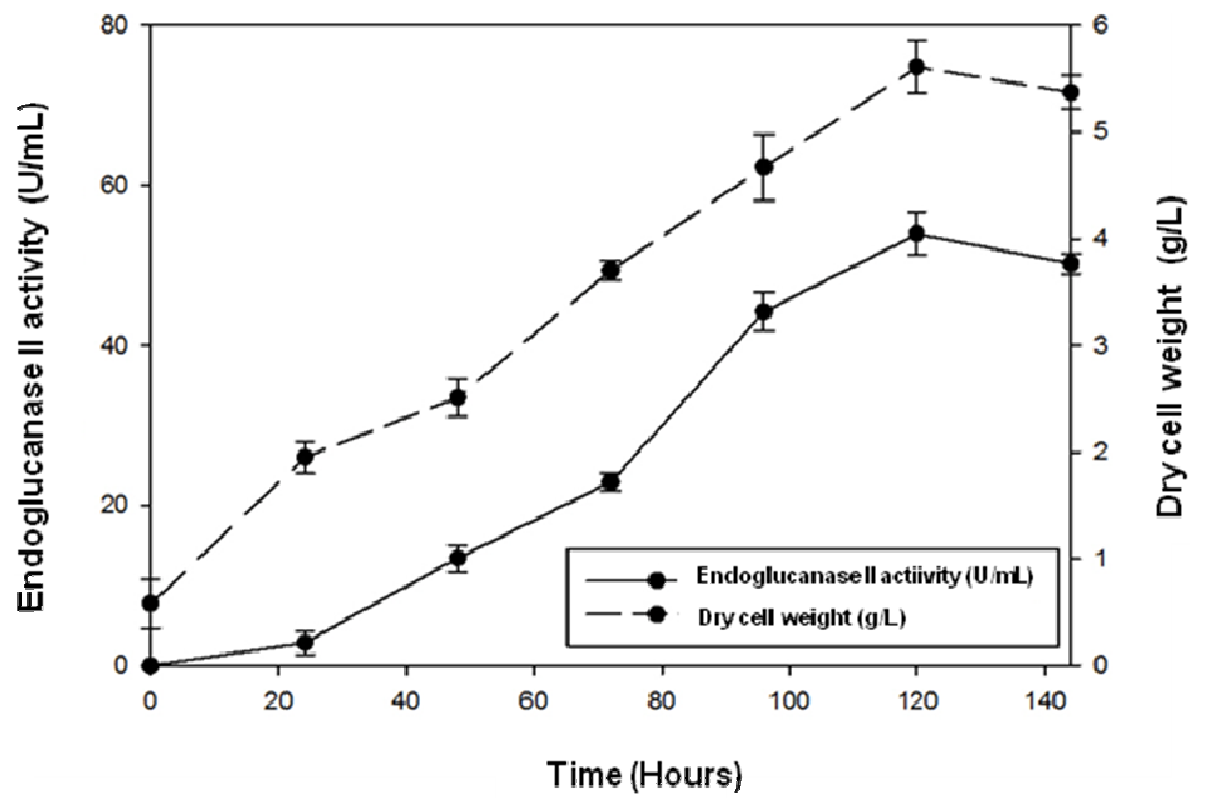

Figure 3. The growth of, and the extracellular recombinant endoglucanase II production $(\mathrm{U} / \mathrm{mL})$ level by, recombinant $P$. pastoris over time when grown in BMM3YSR medium (rice bran hydrolysate at $0.15 \%(\mathrm{w} / \mathrm{v})$ as a replacement for yeast extract in $\mathrm{BMM}_{3} \mathrm{YS}$ media). Data are shown as the mean $\pm 1 \mathrm{SD}$ and are derived from triplicate experiments.

Table 4. Effect of ammonium sulfate as an inorganic nitrogen supplement in the BMcGYTRS $^{a}$ medium on the growth of recombinant $P$. pastoris.

\begin{tabular}{lc}
\hline $\begin{array}{l}\text { Ammonium sulfate } \\
(\%(\mathbf{w} / \mathbf{v}))\end{array}$ & $\begin{array}{c}\text { Dry cell weight } \\
(\mathbf{g} / \mathbf{L})^{\mathbf{b}}\end{array}$ \\
\hline 0.00 & $4.52 \pm 0.07$ \\
0.10 & $8.26 \pm 0.47$ \\
0.25 & $8.30 \pm 0.12$ \\
0.50 & $8.34 \pm 0.18$ \\
1.00 & $7.81 \pm 0.26$ \\
1.50 & $7.66 \pm 0.09$ \\
2.00 & $7.76 \pm 0.13$ \\
\hline
\end{tabular}

${ }^{\mathrm{a}} \mathrm{BMCGYRS}=\mathrm{BMGY}$ medium but with the $2 \%(\mathrm{v} / \mathrm{v})$ pure glycerol, $1 \%(\mathrm{w} / \mathrm{v})$ peptone and $2 \%(\mathrm{w} / \mathrm{v})$ yeast extract replaced with $1 \%$ $(\mathrm{v} / \mathrm{v})$ crude glycerol $(75 \%(\mathrm{v} / \mathrm{v})$ glycerol) from a biodiesel production plant, $0.175 \%(\mathrm{v} / \mathrm{v})$ soy meal hydrolysate and $0.15 \%(\mathrm{v} / \mathrm{v})$ rice bran hydrolysate, respectively. ${ }^{\mathrm{b}} \mathrm{Data}$ are shown as the mean $\pm 1 \mathrm{SD}$ and are derived from triplicate experiments. Means followed by a different lowercase letter are significantly different $(P<0.05$; ANOVA, DMRT).

high an extent as in the other media. A maximum rEGII level $(54.0 \mathrm{U} / \mathrm{mL})$ was obtained after $120 \mathrm{~h}$ (Figure 3). Although the maximum level of obtained rEGII was 1.11and 1.27-fold lower than the maximum amount obtained in the $\mathrm{BMM}_{3} \mathrm{YS}$ and $\mathrm{BMM}_{3} \mathrm{Y}$ media, respectively, this loss of yield was still not as great as the likely financial savings gained ( 98.4\%; http://www.alibaba.com/RiceBran and HiMedia Laboratories Pvt. Ltd.). Therefore, the mixture of soybean meal and rice bran hydrolysates is a cheap nitrogen source that could be used for enzyme production.

\section{Effect of the inorganic nitrogen source}

The effect of supplementing the BMcGYSR medium with ammonium sulphate, as an inorganic nitrogen source, on the growth of $P$. pastoris was evaluated over the range of $0-2 \%(w / v)$. Increasing the ammonium sulphate concentration up to $0.5 \%(\mathrm{w} / \mathrm{v})$ caused an increased yield of yeast, reaching a maximum of $8.34 \mathrm{~g} / \mathrm{L}$ (DCW basis) (Table 4). Further increasing the ammonium sulphate concentration above $0.5 \%(\mathrm{w} / \mathrm{v})$ reduced the yeast yield and so $0.5 \%(\mathrm{w} / \mathrm{v})$ was taken as optimal for both media (hereafter called BMcGYSRA and $\mathrm{BMM}_{3}$ YSRA).

When the recombinant $P$. pastoris was cultured and induced in the $\mathrm{BMM}_{3} \mathrm{YSRA}$ medium an increased yeast yield and rEGIl production level, 1.1-fold to $6.53 \mathrm{~g} / \mathrm{L}$ and $61.7 \mathrm{U} / \mathrm{mL}$, respectively was observed as compared to that in the $\mathrm{BMM}_{3} \mathrm{YSR}$ medium without ammonium sulphate (Figure 4). This result is in agreement with previous reports that too high or too low ammonium ion concentration in the culture medium leads to a reduced cell growth (Cos et al., 2006; Yalcin and Ozbas, 2008). 




Figure 4. The growth of, and the extracellular recombinant endoglucanase II production $(\mathrm{U} / \mathrm{mL})$ level by, recombinant $P$. pastoris over time when grown in $\mathrm{BMM}_{3} \mathrm{YSRA}$ media $\left(\mathrm{BMM}_{3} \mathrm{YSR}\right.$ with $0.5(\mathrm{w} / \mathrm{v})$ ammonium sulphate). Data are shown as the mean $\pm 1 \mathrm{SD}$ and are derived from triplicate experiments.

Table 5. Effect of the medium $\mathrm{pH}$ on the growth of, and recombinant endoglucanase II production $(\mathrm{U} / \mathrm{mL})$ level by, recombinant $P$. pastoris in $\mathrm{BMM}_{3} \mathrm{YRSA}^{\mathrm{a}}$ medium.

\begin{tabular}{ccc}
\hline pH & $\begin{array}{c}\text { Dry cell weight } \\
(\mathbf{g} / \mathbf{L})^{\mathbf{b}}\end{array}$ & $\begin{array}{c}\text { Endoglucanase Il activity } \\
(\mathbf{U} / \mathbf{m L})^{\mathbf{b}}\end{array}$ \\
\hline 5.5 & $6.57 \pm 0.18$ & $60.30 \pm 0.33$ \\
6.0 & $6.61 \pm 0.04$ & $61.42 \pm 2.28$ \\
6.5 & $6.73 \pm 0.22$ & $24.07 \pm 2.78$ \\
7.0 & $6.69 \pm 0.22$ & $19.78 \pm 2.07$ \\
\hline
\end{tabular}

${ }^{\mathrm{a}} \mathrm{BMM}_{3} \mathrm{YRSA}=\mathrm{BMMY}$ medium but with the $0.5 \%(\mathrm{v} / \mathrm{v})$ methanol, $1 \%(\mathrm{w} / \mathrm{v})$ peptone and $2 \%(\mathrm{w} / \mathrm{v})$ yeast extract and replaced with $3 \%(\mathrm{v} / \mathrm{v})$ methanol, $0.175 \%(\mathrm{v} / \mathrm{v})$ soy meal hydrolysate and $0.15 \%(\mathrm{v} / \mathrm{v})$ rice bran hydrolysate, respectively, and supplemented with $0.5 \%(\mathrm{w} / \mathrm{v})$ ammonium sulphate; ${ }^{b}$ Data are shown as the mean \pm 1 SD and are derived from triplicate experiments. Means followed by a different lowercase letter are significantly different $(P<$ 0.05; ANOVA, DMRT).

\section{Effect of the culture medium $\mathrm{pH}$}

With respect to the medium $\mathrm{pH}$, no significant effect on the recombinant $P$. pastoris yield in the $\mathrm{BMM}_{3} \mathrm{YSRA}$ medium was observed at $\mathrm{pH}$ values between 5.5 and 7.0 (Table 5). This is consistent with the reported ability of $P$. pastoris to grow within the $\mathrm{pH}$ range of 3.0-7.0 (Inan et al., 1999; Bayraktar, 2009). However, the level of obtained extracellular rEGII activity was markedly reduced at $\mathrm{pH} 6.5$ ( 2.5-fold) and $\mathrm{pH} 7.0$ ( 3.1-fold) as compared to that at $\mathrm{pH}$ 5.5-6.0 (Table 5), which may
Table 6. Effect of the incubation temperature on the growth of, and recombinant endoglucanase II production $(\mathrm{U} / \mathrm{mL})$ level by, recombinant $P$. pastoris in $\mathrm{BMM}_{3} \mathrm{YRSA}^{\mathrm{a}}$ medium.

\begin{tabular}{lcc}
\hline $\begin{array}{l}\text { Temperature } \\
\left({ }^{\circ} \mathbf{C}\right)\end{array}$ & $\begin{array}{c}\text { Dry cell weight } \\
(\mathbf{g} / \mathbf{L})^{\mathbf{b}}\end{array}$ & $\begin{array}{c}\text { Endoglucanase II activity } \\
(\mathbf{U} / \mathbf{m L})^{\mathbf{b}}\end{array}$ \\
\hline 25 & $6.21 \pm 0.12$ & $58.95 \pm 1.45$ \\
30 & $6.67 \pm 0.26$ & $61.49 \pm 0.25$ \\
35 & $1.17 \pm 0.09$ & $7.87 \pm 0.14$ \\
\hline
\end{tabular}

${ }^{\mathrm{a}} \mathrm{BMM}_{3} \mathrm{YRSA}=$ as per Table $5 ;{ }^{\mathrm{b}}$ Data are shown as the mean $\pm 1 \mathrm{SD}$ and are derived from triplicate experiments. Means followed by a different lowercase letter are significantly different $(P<0.05$; ANOVA, DMRT).

reflect a higher protease activity in the culture medium or a decreased enzyme stability at the higher $\mathrm{pH}$ values (Cos et al., 2006).

\section{Effect of incubation temperature}

With respect to the cultivation temperature, the optimal yeast growth (as DCW) and rEGIl production level was obtained at $30^{\circ} \mathrm{C}$ for the culturing and induction of the recombinant $P$. pastoris in the $\mathrm{BMM}_{3}$ YSRA medium (Table 6). Increasing the culture temperature from 30 to $35^{\circ} \mathrm{C}$ resulted in a marked (5.7- and 7.8-fold) decrease in the yeast and rEGII yields obtained, respectively. In agreement, it has previously been reported that $30^{\circ} \mathrm{C}$ was the most appropriate template for the growth of, and enzyme production by, P. pastoris in general (Shi et al., 2003; Macauley et al., 2005; Rahbarizadeh et al., 2006). 


\section{Conclusions}

The culturing of recombinant $P$. pastoris for the production of rEGIl was attained using BMcGYRS and $\mathrm{BMM}_{3}$ YRS media, which are the use of a $1 \%(\mathrm{v} / \mathrm{v})$ crude glycerol $(75 \%(\mathrm{v} / \mathrm{v})$ glycerol content from a biodiesel production plant) plus $0.175 \%(\mathrm{v} / \mathrm{v})$ soybean meal and $0.15 \%(\mathrm{v} / \mathrm{v})$ rice bran hydrolysates as a replacement for the $2 \%(\mathrm{v} / \mathrm{v})$ glycerol, $2 \%(\mathrm{w} / \mathrm{v})$ peptone and $1 \%(\mathrm{w} / \mathrm{v})$ yeast extract in standard BMGY and BMMY media, respectively. Although the optimal rEGII production required supplementation of this modified medium with $0.5 \%(\mathrm{w} / \mathrm{v})$ ammonium sulphate, overall these media will provide a likely economic advantage for the industrial scale production of recombinant enzymes by $P$. pastoris.

\section{Conflict of Interests}

The author(s) have not declared any conflict of interests.

\section{ACKNOWLEDGEMENTS}

This study was supported by the PTT Research and Technology Institute, PTT Public Co. Ltd., Thailand, and by the Biofuel by Biocatalysts Research Unit, Department of Botany, Faculty of Science, Chulalongkorn University. We would like to thank Dr. Robert Butcher from Publication Counseling Unit, Chulalongkorn University for the comments on the manuscript and English proofreading

\section{REFERENCES}

AOAC (1990). Official methods of analysis. Association of Official Analytical Chemistry ( $15^{\text {th }}$ edition). (K. Helrick, editor). Arlington. 1230.

Batista KA, Bataus LM, Campos TN, Fernandes FK (2013). Development of culture medium using extruded bean as a nitrogen source for yeast growth. J. Microbiol. Methods 92:310-315.

Bayraktar E (2009). Effects of $\mathrm{pH}$ on human growth hormone production by Pichia pastoris considering the expression levels of regulatory genes. Master's Thesis. University of Middle East Technical.

Boonvitthya N, Bozonnet S, Burapatana V, O'Donohue MJ, Chulalaksananukul W (2013). Comparison of the heterologous expression of Trichoderma reesei endoglucanase II and cellobiohydrolase II in the yeasts Pichia pastoris and Yarrowia lipolytica. J. Mol. Biotechnol. 54:158-169.

Bradford MM (1976). A rapid and sensitive method for the quantitation of microgram quantities of protein utilizing the principle of protein-dye binding. Anal. Biochem. 72:248-254.

Broach RJ (2012). Nutritional control of growth and development in yeast. Genetics 192:73-105.

Bushell ME, Rowe M, Avignone-Rossa CA, Wardell JN (2003). Cyclic fed-batch culture for production of human serum albumin in Pichia pastoris. Biotechnol. Bioeng. 82:678-683.

Celik E, Ozbay N, Oktar N, Cahk P (2008). Use of biodiesel byproduct crude glycerol as the carbon source for fermentation processes by recombinant Pichia pastoris. Ind. Eng. Chem. Res. 47:2985-2990.

Charoenrat T, Khumruaengsri N, Promdonkoy P, Rattanaphan N, Eurwilaichitr L, Tanapongpipat S, Roongsawang N (2013). Improvement of recombinant endoglucanase produced in Pichia pastoris KM71 through the use of synthetic medium for inoculums and $\mathrm{pH}$ control of proteolysis. J. Biosci. Bioeng. 116:193-198.
Chatzifragkou A, Makri A, Belka A, Bellou S, Mavrou M (2011) Biotechnological conversions of biodiesel derived waste glycerol by yeast and fungal species. Energy 36:1097-1108.

Cos O, Ramon R, Montesinos JL, Valero F (2006). Operational strategies, monitoring and control of heterologous protein production in the methylotrophic yeast Pichia pastoris under different promoters: A review. Microb. Cell Fact. 5:17.

Hajii M, Rebai A, Gharsallah N, Narsi M (2008). Optimization of alcaline protease production by Aspergillus clavatus ES1 in Mirabilis jalapa tuber powder using statistical experimental design. Appl. Microbiol. Biotechnol. 79:915-923.

Inan M, Chiruvolu V, Eskridge KM, Vlasuk GP, Dickerson K (1999). Optimization of temperature-glycerol-pH conditions for fed-batch fermentation process for recombinant hookworm (Ancylostoma caninurn) anticoagulant peptide (AcAP-5) production by Pichia pastoris. Enzyme Microb. Technol. 24:438-445.

Kitcha S, Cheirsilp B (2011). Screening of Oleaginous Yeasts and Optimization for Lipid Production Using Crude Glycerol as a Carbon Source. Energy Procedia 9:274-282.

Macauley PS, Fazenda ML, Maneil B, Harvey LM (2005). Heterologous protein production using the Pichia pastoris expression system. Yeast 22:249-270.

Miller GL (1959). Use of dinitrosalicylic acid reagent for determination of reducing sugar. Anal. Chem. 31:426-428.

Naresh P, Brian H (2006). Value-added Utilization of Crude Glycerol from Biodiesel Production: A Survey of Current Research Activities; Biological and Agricultural Engineering, University of Idaho, Moscow, Idaho 83844-2060, Written for presentation at the 2006 ASABE Annual International Meeting Sponsored by ASABE Oregon Convention Center Portland, Oregon 9 - 12 July 2006.

Papanikolaou S, Muniglia L, Chevalot I, Aggelis G, Marc I (2002). Yarrowia lipolytica as a potential producer of citric acid from raw glycerol. J. Appl. Microbiol. 92: 737-744.

Petitdemange E, Dürr C, Abbad Andaloussi S, Raval G (1995). Fermentation of raw glycerol to 1,3-propanediol by new strains of Clostridium butyricum. JIMB 15: 498-502.

Qin Y, Wei X, Liu X, Wong T, Qu Y (2008). Purification and characterization of recombinant endoglucanase of Trichoderma reesei expressed in Saccharomyces cerevisiae with higher glycosylation and stability. Protein Expr. Purif. 58:162-167.

Rahbarizadeh F, Rasaee MJ, Forouzandeh M, Allameh AA (2006). Over expression of anti-MUCl single-domain antibody fragments in the yeast Pichia pastoris. Mol. Immunol. 43:426-435.

Sereewatthanawut I, Prapintip S, Watchiraruji K, Goto M, Sasaki M, Shotipruk A (2008). Extraction of protein and amino acids from deoiled rice bran by subcritical water hydrolysis. J. Bioresour. Technol. 99: 555-561.

Shi X, Karkut T, Chamankhah M, Alting-Mee M, Hemmingsen SM, Hegedus D (2003). Optimal conditions for the expression of a singlechain antibody (scFv) gene in Pichia pastoris. Protein Expr. Purif. 28: 321-330.

Tang S, Boehme L, Lam H, Zhang Z (2009). Pichia pastoris fermentation for phytase production using crude glycerol from biodiesel production as the sole carbon source. Biochem. Eng. 43: 157-162.

Xiao ZJ, Liu PH, Qin JY, Xu P (2007). Statistical optimization of medium components for enhanced acetoin production from molasses and soybean meal hydrolysate. Appl. Microbiol. Biotechnol. 74: 61-68.

Yadav K, Dhiman S, Baruah I, Singh L (2011). Development of cost effective medium for production of Bacillus sphaericus strain isolated from Assam, India. J. Microbiol. 1: 65-70.

Yalcin SK, Ozbas ZY (2008). Effects of ammonium sulphate concentration on growth and glycerol production kinetics of two endogenic wine yeast strains. India. J. Microbiol. 7: 89-93.

Zhang W, Liu C, Wang G, Ma Y, Zhang K, Zou S, Zhang M (2012). Comparison of the expression in Saccharomyces cerevisiae of endoglucanase II from Trichoderma reesei and endoglucanase I from Aspergillus aculeatus. Bioresources 7: 4031-4045. 